\title{
DIFERENÇAS COMPORTAMENTAIS DE POEDEIRAS EM DIFERENTES AMBIENTES TÉRMICOS
}

\author{
Danilo Florentino Pereira ${ }^{1}$, Edna dos Santos Batista ${ }^{2}$, Filipe Teixeira Sanches ${ }^{3}$, Luis Roberto \\ Almeida Gabriel Filho ${ }^{4} \&$ Leda Gobbo de Freitas Bueno ${ }^{5}$
}

RESUMO: O microclima no interior da instalação avícola é um dos fatores responsáveis pelo sucesso do empreendimento e afeta o comportamento da ave. Assim, o objetivo deste experimento foi verificar como o ambiente térmico proporcionado em aviários influencia o comportamento das poedeiras. $\mathrm{O}$ experimento foi realizado em galpões de escala reduzida e distorcida com poedeiras de idade entre 30 e 32 semanas. As aves foram criadas em boxes com cama de maravalha, poleiro e ninho, em dois grupos diferentes (6 e 12 aves) e duas densidades diferentes (774 e 1440 $\mathrm{cm}^{2}$ ave-1). As frequências e tempos de expressão dos comportamentos foram registrados nos últimos três dias de cada semana em amostras de vídeo de 15 minutos. Os resultados indicam que o ambiente térmico influenciou o comportamento das aves e que a quantificação desses comportamentos possibilitam conhecer o bem-estar das poedeiras.

PALAVRAS-CHAVE: ambiente enriquecido, bem estar animal, zootecnia de precisão.

\section{Behavioral differences of laying hens reared in different thermal environments}

ABSTRACT: The microclimate inside the poultry facility is one of the factors responsible for the success of the venture and affects the behavior of the bird. The objective of this experiment was to determine how the thermal environment provided in aviaries influences the behavior of laying hens. The experiment was conducted in sheds of distorted and reduced scale, with laying hens of ages between 30 and 32 weeks. The birds were raised in pens with wood shavings bedding, perch and nest in two different groups ( 6 and 12 birds) and two different densities ( 774 and $1440 \mathrm{~cm}^{2}$ bird-1). The behavior frequency and expressions were recorded during the last three days of each week in video samples of 15 minutes. The results indicate that the thermal environment influenced the behavior of the birds and the quantification of these allows the knowledge of the welfare of laying hens.

KEYWORDS: Enrichment ambiance, animal welfare, and precision poultry production.

\section{INTRODUÇÃO}

O bem-estar animal é aspecto importante para a produção avícola, sendo uma das exigências à comercialização em muitos dos mercados internacionais, além de agregar valor ao produto final. $\mathrm{O}$ conhecimento e o controle do microclima gerado no interior da instalação é um dos fatores responsáveis pelo sucesso do empreendimento (Pereira, 2011).

Na literatura já é citado que há perdas produtivas, provenientes de galpões avícolas instalados em climas com temperaturas diárias elevadas, e que as mesmas são significativas, pois abrangem perdas diretas e indiretas. Salgado \& Nääs (2010) através de dados históricos meteorológicos de temperaturas diárias avaliaram o risco

\footnotetext{
${ }^{1}$ Universidade Estadual Paulista Júlio de Mesquita Filho, Campus Experimental de Tupã. E-mail: danilo@tupa.unesp.br

${ }^{2}$ E-mail: ednasantosbatista@gmail.com

${ }^{3}$ E-mail: sanchesft@ hotmail.com

${ }^{4}$ E-mail: gabrielfilho@tupa.unesp.br

${ }^{5}$ Universidade Estadual Paulista Júlio de Mesquita Filho, Campus

Experimental de Dracena E-mail: leda@ dracena.unesp.br
}

à produção de frango de corte do Estado de São Paulo e verificaram que os municípios da região oeste do Estado são os mais suscetíveis a apresentarem perda na produção avícola devido às temperaturas ambientais.

Nesta região, faz-se necessária a redução de perdas produtivas, principalmente nas fases finais de criação, sobretudo quando provocada pelo estresse térmico (Tankson et al., 2001).

A observação e a avaliação dos comportamentos expressos pelas aves pode ajudar na estimativa do bem estar das aves. De acordo com Becker (2002), o bem estar animal é avaliado de acordo com parâmetros fisiológicos e comportamentais. No caso de aves poedeiras, a utilização de caixas-ninho é uma parte importante do repertório comportamental desses animais e deveria ser garantido em condições comerciais para se minimizar o estresse pela frustração e melhorar a das aves (Riber, 2010). 
De acordo com Campos et al. (2005), locais em que a temperatura média do ar é elevada tende a apresentar menor produção, fato que se acentua ainda mais no período de verão. Além de provocar redução na taxa de postura, esta condição provoca redução no peso e na qualidade dos ovos que afetam progressivamente a qualidade externa do ovo como percentagem de casca, espessura de casca e gravidade específica do ovo.

O objetivo desta pesquisa foi verificar como o ambiente térmico influencia o comportamento das poedeiras, considerando duas densidades e dois tamanhos de grupo.

\section{MATERIAL E MÉTODOS}

A pesquisa foi realizada em dois galpões de escala reduzida e distorcida localizados no Campus de Tupã da UNESP. O clima da região é tropical, com estação seca bem definida no período de inverno e temperaturas médias anuais maiores que $22^{\circ} \mathrm{C}$.

O experimento foi repetido três vezes para grupos diferentes de aves. A primeira repetição foi conduzida durante o mês de maio de 2010, a segunda repetição durante os meses de novembro e dezembro de 2010 e a terceira repetição no mês de janeiro de 2011. Cada repetição durou 28 dias, sendo que os primeiros sete dias foram dedicados a adaptação das aves ao novo ambiente

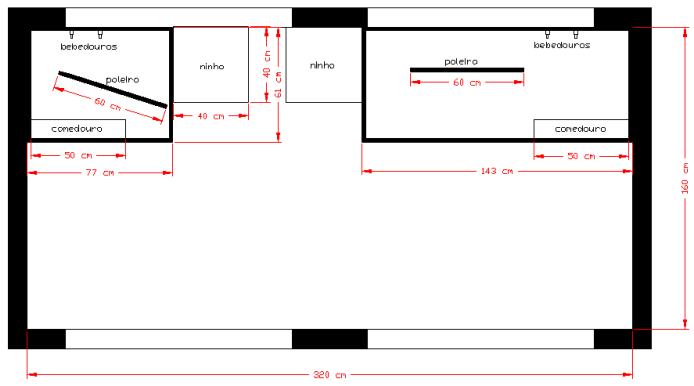

A) de criação. As repetições proporcionaram ambientes térmicos distintos, sendo considerado um fator na análise comparativa.

Em cada repetição do experimento foram utilizadas 36 galinhas da linhagem Isa Brown com idade inicial entre 30 e 32 semanas, obtidas em granjas comerciais da região.

As aves foram alojadas em dois tamanhos de grupos (6 e 12 aves) e em duas densidades, que tiveram pequenas variações decorrentes das áreas dos boxes construídos: $766 \mathrm{~cm}^{2}$ ave-1 a $782 \mathrm{~cm}^{2}$ ave-1 e $1.426 \mathrm{~cm}^{2}$ ave-1 a $1.453 \mathrm{~cm}^{2}$ ave-1.

Cada galpão foi dividido em compartimentos (boxes). Todos os boxes foram enriquecidos, com ninho e poleiro, além da cama de maravalha em toda a área. Nos boxes que receberam os grupos menores de aves ( 6 aves) foram dispostos dois bebedouros tipo nipple, $50 \mathrm{~cm}$ de comedouro, um ninho de 40 x $40 \mathrm{~cm}$ e $60 \mathrm{~cm}$ de poleiro. Nos boxes que receberam os grupos maiores de aves (12 aves) foram dispostos quatro bebedouros tipo nipple, 100 $\mathrm{cm}$ de comedouro, um ninho de 40 x $40 \mathrm{~cm}$ e $120 \mathrm{~cm}$ de poleiro. A disposição dos equipamentos e objetos de enriquecimento pode ser observada na Figura 1.

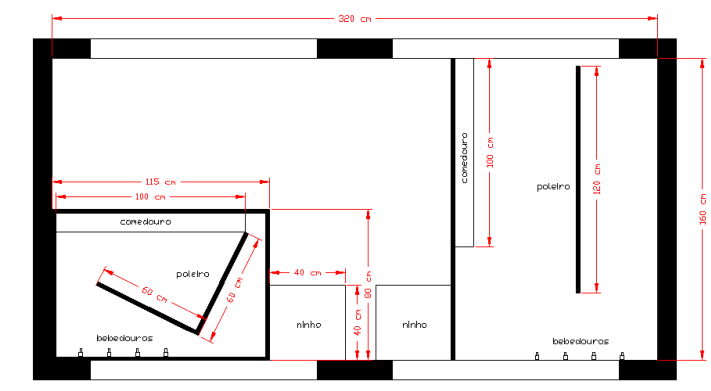

B)

Figura 01 - Esquema dos boxes dentro dos galpões. A) para grupos de seis aves e B) para grupos de 12 aves

Durante os experimentos todas as aves foram submetidas ao mesmo manejo de luz e a ração foi fornecida ad libitum. O iluminamento dos boxes era provido por lâmpadas incandescentes e luz natural, entre 4:00 e 21:00, completando um fotoperíodo de 17 horas de luz, reproduzindo o manejo praticado na granja de origem das aves.

No teto dos galpões em escala reduzida e distorcida foi instalada uma câmera de vídeo sobre cada box, modelo Mythos CCD Color, com lente de 1,5mm, para os boxes de área menor, e 2,5mm, para os boxes de área maior. Essas câmeras foram conectadas a placa de captura de vídeo instalada em computador, distante cerca de $30 \mathrm{~m}$, instalado no Laboratório de Conforto Ambiental do Campus de Tupã da UNESP.

Foram observados os comportamentos descritos no etograma da Tabela 1 por meio dessas câmaras de vídeo, obtendo-se amostras diárias de filmagem de 15 minutos durante o período da manhã (entre 9:00 e 10:00) e 15 minutos durante o período da tarde (entre 15:00 e 16:00), durante quatro semanas consecutivas em cada repetição. Os vídeos analisados constavam dos três últimos dias, totalizando seis horas de filmagem para cada tratamento combinado de densidade e tamanho de grupo em cada repetição. 
Tabela 1 - Descrição dos comportamentos observados e analisados.

\begin{tabular}{lll}
\hline Comportamento & Descrição & Unidade de medida \\
\hline Arrumar penas & Atividade em que a ave limpa e arruma as penas com o bico. & Frequência e tempo \\
Banho de areia & Atividade em que a ave joga sobre seu corpo o material da cama. & Frequência e tempo \\
Bater asas & Movimento em que a ave bate as duas asas. & Frequência \\
Beber água & Atividade em que a ave bebe água no bebedouro. & Frequência e tempo \\
Bicar & $\begin{array}{l}\text { Comportamento em que uma ave bica qualquer parte do corpo de outra } \\
\text { ave de forma agressiva. }\end{array}$ & Frequência \\
Ciscar & $\begin{array}{l}\text { Atividade da ave procurar alimento na cama utilizando as patas e o o } \\
\text { bico }\end{array}$ & Frequência e tempo \\
Coçar a cabeça & Comportamento em que a ave coça a cabeça com uma das patas. & Frequência \\
Comer & Atividade da ave comendo no comedouro. & Frequência e tempo \\
Empoleirar & Comportamento em que a ave sobe e/ou permanece sobre o poleiro. & Frequência e tempo \\
Esticar perna & $\begin{array}{l}\text { Comportamento em que a ave estica uma asa e uma perna, do mesmo } \\
\text { hemisfério do corpo. }\end{array}$ & Frequência \\
Ninho & Comportamento da ave ficar dentro do ninho para ovoposição. & Frequência e tempo \\
Perseguir & $\begin{array}{l}\text { Ato em que uma ave corre atrás de outra ave com intenção aparente de } \\
\text { agressão. }\end{array}$ & Frequência e tempo \\
Sentar & Ato da ave de ficar sentada ou deitada. & Frequência e tempo
\end{tabular}

Foram registradas as frequências de ocorrências para todos os comportamentos descritos no etograma da Tabela 1. Para os comportamentos que são expressos por um tempo maior, foram registrados os tempos de expressão de cada ocorrência em segundos.

Para os registros dos comportamentos expressos em frequência foram calculadas as médias de ocorrências pelo número de aves alojadas em cada tratamento em cada vídeo gravado. Para os registros de tempos de duração dos comportamentos, calcularam-se as médias dos tempos de duração de cada vídeo em função do número de ocorrências do respectivo comportamento.

Para o monitoramento do ambiente, foi instalado no centro geométrico de cada galpão um datalogger modelo HOBO da fabricante Onset ${ }^{\circledR}$ e registrou-se a cada 15 minutos a temperatura de bulbo seco, a umidade relativa do ar e a temperatura de globo negro. A partir dos dados do ambiente térmico interno dos galpões, calculou-se o Índice de Temperatura e Umidade (ITGU) a partir da fórmula mostrada na equação (1). Os dados do ambiente foram comparados entre os galpões para verificar possíveis diferenças significativas que pudessem afetar os comportamentos das aves.

$$
I T G U=T g n+0,36 \cdot T p o-330,08
$$

Onde: $\operatorname{Tgn}=$ temperatura de globo negro $(K) ; T p o=$ temperatura de ponto de orvalho ( $K$ ).
Para verificar os efeitos dos tratamentos (densidade e tamanho do grupo) nas frequências e tempos de duração dos comportamentos observados, aplicou-se o teste nãoparamétrico de Kruskal-Wallis para comparação das medianas de postos dos tratamentos.

Alguns comportamentos não apareceram em todos os vídeos gravados e alguns comportamentos foram bastante raros. Portanto, a ocorrência desses comportamentos nos horários de gravação dos vídeos pode indicar diferenças significativas decorrentes dos tratamentos testados. Para essa análise foram elaboradas tabelas de contingência sistematizando o número de vídeos em que se observou determinado comportamento, para cada fator de análise. Para essas tabelas de contingência aplicou-se o teste de qui-quadrado $\left(\chi^{2}\right)$ para verificar se a dependência dos fatores.

\section{RESULTADOS E DISCUSSÃO}

A A Figura 2 mostra a variação do ITGU em cada galpão para cada repetição. Observa-se que na repetição 1 o ambiente foi mais ameno e que na repetição 3 houve maior frequência de registros acima do limite superior da zona de termoneutralidade. A partir desses resultados, considerou-se que o ambiente térmico na repetição 3 foi pior que na repetição 2 , que por sua vez foi pior que na repetição 1 . 


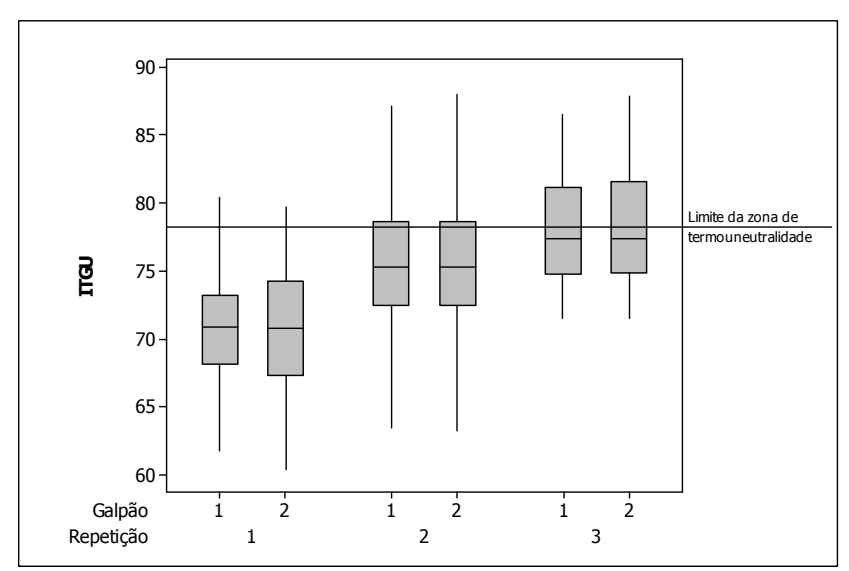

\section{Figura 2 - Variação do ITGU em cada galpão e repetição do experimento.}

O ambiente ao qual a ave está submetida influencia fortemente no comportamento (Dawkins, 1999; Ferrante et al., 2001), pois o mecanismo de homeostase somente é eficiente quando as temperaturas estão próximas. Adquirindo-se o conhecimento de como este ambiente atua sobre a homeostase é possível identificar, quantificar e caracterizar as condições de conforto térmico e bem estar (Pereira, et al., 2007).

As aves, quando estão em estresse, alteram seu comportamento para auxiliar na manutenção da temperatura corporal dentro de limites normais (Pereira et al., 2007). Assim dependendo da condição bioclimática do ambiente em que este animal está inserido, podem ser visualizados comportamentos considerados normais ou mesmo apresentar desvios por estresse calórico.

Considerando 78 como o limite de conforto do ITGU (Armstrong, 1994), verifica-se que as medianas de cada galpão de todas as repetições do experimento ficaram abaixo desse limite. Entretanto, observa-se que houve um aquecimento da primeira para a segunda repetição e da segunda para a terceira repetição. Observa-se também que os terceiros quartis da segunda e da terceira repetição ficaram acima do limite de termoneutralidade, o que denota que nessas repetições tiveram o ambiente térmico em alguns horários do dia acima do limite de termoneutralidade, podendo afetar o comportamento das aves entre as repetições.

Medeiros et al., (2005) verificaram que as aves quando foram mantidas em ambientes quentes (ITGU 78 a 88) ficaram agitadas, abriram mais as asas e se dispersaram para aumentar a dissipação de calor corporal para o ambiente. Notou-se também um aumento na temperatura retal de $1,3^{\circ} \mathrm{C}$ e de $2,8^{\circ} \mathrm{C}$ para a temperatura da pele, além do aumento da frequência respiratória em 28 resp $\min ^{-1}$.
Alves (2006) afirma que em casos de desconforto térmico devido a ambientes acima da zona de termoneutralidade, comportamentos como ciscar e abrir asas são reduzidos.

Foram observadas diferenças significativas nos comportamentos das poedeiras entre as repetições do experimento (Tabela 2). Os comportamentos comer, beber água, ciscar e arrumar penas tiveram uma diminuição na frequência de expressões na terceira repetição, enquanto que os comportamentos sentar e bicar tiveram um aumento dessas frequências. Estudos mostram diminuição no consumo de ração e maior ingestão de água quando as aves estão em ambientes acima a zona de termoneutralidade, além de aumentarem a frequência de bicar (Alves, 2006; Rodrigues, 2006; Silva et al., 2006; Barbosa Filho et al.; 2007).

Salgado (2006) verificou que o estado de prostação ocorre após o comportamento de espreguiçar. Weeks \& Nicol (2006) observaram uma associação positiva do comportamento "Correr" e "Ciscar". Os comportamentos sofrem também a influência do ambiente térmico a qual a ave está submetida. Campos (2000) cita que quanto mais elevada a temperatura menor a atividade física das aves.

Bracke \& Hopster (2006); Silva et al., (2006); Haas et al., (2010) verificaram que o impedimento ou diminuição do comportamento de ciscar agrava significativamente o estresse da ave, onde aparentemente há uma substituição natural deste comportamento de ciscar, para bicagem de penas, variando a intensidade de acordo com a linhagem e a idade do lote. No sistema de criação em gaiola, mesmo depois de estabelecida uma dominância e hierarquia dentro do grupo de poedeiras, as aves continuaram apresentando agressividade, indicando maior carga de estresse no sistema de criação em confinamento. De acordo com Nicol et al., (2009) as galinhas têm preferência por ambientes onde lhes são oferecidas oportunidades de ciscar e limpar penas.

Segundo Schwean-Lardner \& Classen, (2010), comportamentos que denotam atividade física podem ser utilizados para se conhecer o estado sanitário e de conforto e ou bem-estar. Comportamentos que exprimam atividade física são considerados em algumas situações indicadores de estresse. Relacionado também a expressão de bem-estar, mas considerados como comportamentos inerentes e ou ingestivos, estão o de ciscar, limpar penas, tomar banho, beber água e comer (Pereira et al. 2005; Silva et al., 2006; Salgado et al., 2007; Weeks \& Nicol, 2006; Alvino et al., 2009). 
Tabela 2 - Diferenças entre as ocorrências médias dos comportamentos entre as repetições do experimento, considerando as médias de observações de manhã e tarde.

\begin{tabular}{lccc}
\hline \multirow{2}{*}{ Comportamentos } & \multicolumn{3}{c}{ Repetições } \\
\cline { 2 - 4 } & 1 & 2 & 3 \\
\hline Arrumar penas & $3,41^{\mathrm{a}}$ & $1,50^{\mathrm{b}}$ & $0,83^{\mathrm{c}}$ \\
Banho de areia & 0,08 & 0,08 & 0,08 \\
Bater asas & 0,17 & 0,17 & 0,17 \\
Beber água & $3,42^{\mathrm{b}}$ & $4,96^{\mathrm{a}}$ & $1,38^{\mathrm{c}}$ \\
Bicar severo & $0,17^{\mathrm{b}}$ & $0,17^{\mathrm{b}}$ & $0,67^{\mathrm{a}}$ \\
Ciscar & $0,50^{\mathrm{b}}$ & $1,17^{\mathrm{a}}$ & $0,50^{\mathrm{b}}$ \\
Coçar a cabeça & & & \\
Comer & $3,00^{\mathrm{a}}$ & $2,67^{\mathrm{a}}$ & $1,79^{\mathrm{b}}$ \\
Empoleirar & $0,17^{\mathrm{a}}$ & $0,08^{\mathrm{b}}$ & $0,17^{\mathrm{ab}}$ \\
Esticar perna & 0,17 & 0,17 & 0,17 \\
Ninho & $0,17^{\mathrm{b}}$ & 0,33 & 0,17 \\
Perseguir & 0,42 & 0,25 & - \\
Sentar & $0,17^{\mathrm{b}}$ & $0,21^{\mathrm{b}}$ & $0,29^{\mathrm{a}}$ \\
\hline
\end{tabular}

Letras diferentes nas linhas indicam diferenças significativas entre as medianas pelo teste de Kruskal-Wallis a $5 \%$ de probabilidade.

Observa-se na Tabela 2 que nas repetições 1 e 2 a frequência dos comportamentos comer e beber água foi maior do que na repetição 3 , no entanto, o inverso aconteceu para o tempo médio de cada comportamento (Tabela 3). Isso é esperado, pois conforme há um aumento na temperatura, as aves tendem a alimentar-se com menor frequência, no entanto, para manter suas exigências, compensam esse fator alimentando-se por maior tempo (Payne, 1967, Campos, 2000). Verifica-se na Tabela 3 que o tempo de cada ocorrência de comer foi aumentado três vezes quando se comparou a segunda com a terceira repetição. Já o comportamento de beber água é aumentado em 10 vezes, o que sugere que as aves consumiram mais água na terceira repetição proporcionalmente ao consumo de ração. $\mathrm{O}$ aumento da ingestão de água em condições de calor também foi relatado por Medeiros et al., (2005); Pereira \& Nääs (2005).

Tabela 3 - Diferenças entre os tempos médios das ocorrências dos comportamentos entre as repetições do experimento, considerando as médias de observações de manhã e tarde.

\begin{tabular}{lccc}
\hline \multirow{2}{*}{ Comportamentos } & \multicolumn{3}{c}{ Repetições } \\
\cline { 2 - 4 } & $\mathbf{1}$ & $\mathbf{2}$ & $\mathbf{3}$ \\
\hline Arrumar penas & $32,00^{\mathrm{b}}$ & $25,00^{\mathrm{b}}$ & $122,00^{\mathrm{a}}$ \\
Banho de areia & $471,00^{\mathrm{a}}$ & $195,50^{\mathrm{b}}$ & - \\
Beber água & $7,00^{\mathrm{b}}$ & $5,00^{\mathrm{c}}$ & $51,00^{\mathrm{a}}$ \\
Ciscar & $38,00^{\mathrm{b}}$ & $47,00^{\mathrm{b}}$ & $113,50^{\mathrm{a}}$ \\
\hline Comer & $84,00^{\mathrm{b}}$ & $49,00^{\mathrm{c}}$ & $166,50^{\mathrm{a}}$ \\
Empoleirar & 313,50 & $107,00^{\mathrm{b}}$ & $599,00^{\mathrm{a}}$ \\
Ninho & $\mathrm{ab}$ & & \\
Sentar & 163.50 & 133.00 & 263.00 \\
\hline
\end{tabular}

Letras diferentes nas linhas indicam diferenças significativas entre as medianas pelo teste de KruskalWallis a $5 \%$ de probabilidade.
Houve um problema na configuração do software para a coleta dos tempos de expressão do comportamento banho de areia na terceira repetição. Por este motivo os dados dessa repetição foram perdidos.

Os tempos de expressão dos comportamentos ciscar, arrumar penas e empoleirar também foram maiores na terceira repetição. Os resultados indicam que o ambiente térmico influenciou nos comportamentos das aves.

Foram observadas diferenças nas frequências dos comportamentos entre os períodos. O comportamento arrumar penas ocorreu com mais frequência no período da manhã e os comportamentos sentar, ciscar e beber água ocorreram com mais frequência no período da tarde (Figura 3).

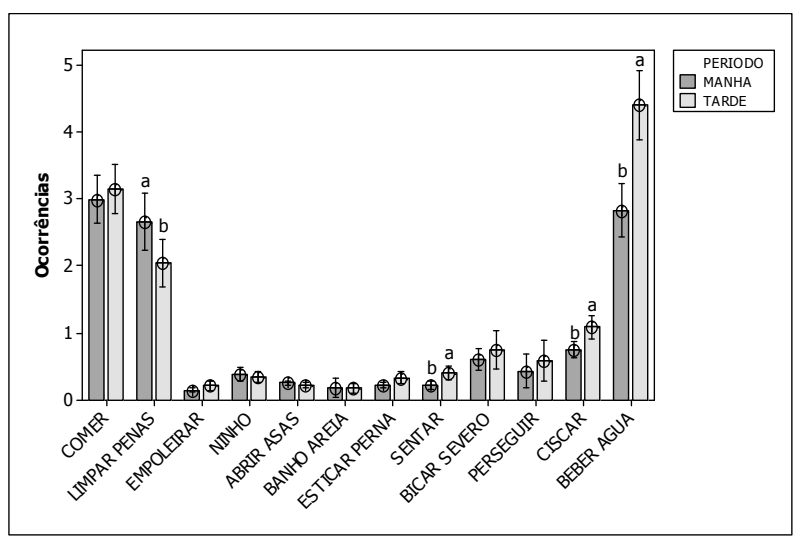

$\begin{aligned} \text { Figura } 3 \text { - } & \text { Frequências de ocorrências dos } \\ & \text { comportamentos nos períodos } \\ & \text { manhã e tarde e diferenças } \\ & \text { significativas pelo teste de Kruskal- } \\ & \text { Wallis a } 5 \% \text { de significância. }\end{aligned}$

Barbosa Filho et al., (2007) observaram que as poedeiras criadas sobre cama apresentaram todos os 
comportamentos naturais relacionados ao bem-estar, enquanto aquelas criadas no sistema tradicional de gaiolas buscavam expressar seus comportamentos naturais, mesmo sem condições para isso, o que levava a frustação e agravava em condições de estresse.

A frequência de uso do ninho não mostrou frequências diferentes entre os períodos, mas o tempo de uso médio foi significativamente maior no período da manhã (Figura 4).

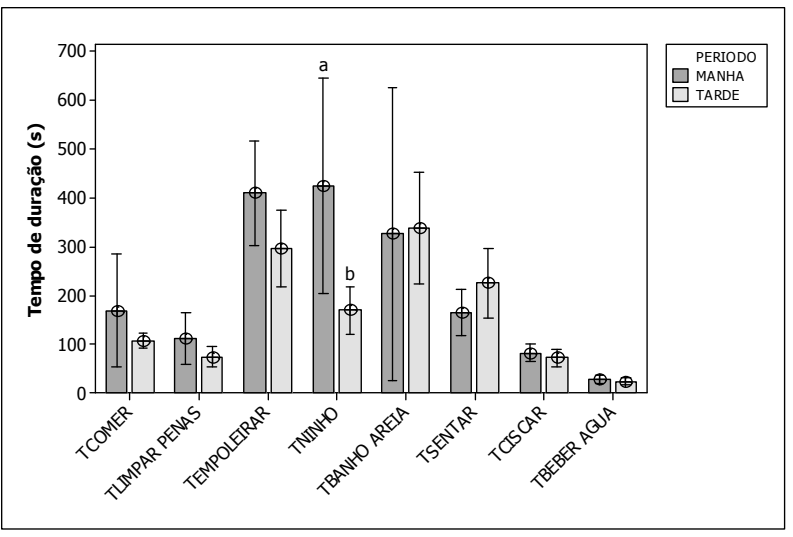

Figura 4 - Tempos de expressão dos comportamentos nos períodos manhã e tarde e diferenças significativas pelo teste de Kruskal-Wallis a $5 \%$ de significância.

Os outros comportamentos não mostraram diferenças significativas nas frequências e no tempo de duração entre os períodos.

Os resultados apresentados se referem às frequências de ocorrências e tempos de duração dos comportamentos observados nos vídeos. Mas nem todos os comportamentos foram observados em todos os vídeos. A Tabela 4 mostra o resultado do teste estatístico de $\chi^{2}$ para as diferenças nas observações no número de vídeos entre os períodos manhã e tarde.

O horário tem grande influência na expressão dos comportamentos das aves (Barbosa Filho et al., 2007), devido ao comportamento biológico e principalmente devido o fotoperíodo. Dependendo do fotoperíodo, haverá mudanças na expressão dos comportamentos das aves. Os mesmos autores observaram que no período da manhã, os comportamentos de ciscar e de procurar o ninho, além do comportamento de empoleirar apareceram em maior porcentagem de tempo (15\%) para linhagem Hy Line W36.
Tabela 4 - Frequência de ocorrências de vídeos com comportamentos raros.

\begin{tabular}{|c|c|c|c|c|}
\hline \multirow{2}{*}{$\begin{array}{l}\text { Comporta } \\
\text { mentos }\end{array}$} & \multicolumn{2}{|l|}{ Período } & \multirow{2}{*}{$\begin{array}{l}\text { Valor do } \\
\text { teste } \chi^{2}\end{array}$} & \multirow{2}{*}{$\mathrm{P}$ valor } \\
\hline & Manhã & Tarde & & \\
\hline $\begin{array}{l}\text { Arrumar } \\
\text { penas }\end{array}$ & 107 & 106 & 0,005 & 0,945 \\
\hline $\begin{array}{l}\text { Banho de } \\
\text { areia }\end{array}$ & 7 & 35 & 18,667 & $\begin{array}{l}<0,001 \\
*\end{array}$ \\
\hline Bater asas & 74 & 62 & 1,059 & 0,303 \\
\hline $\begin{array}{l}\text { Beber } \\
\text { água }\end{array}$ & 107 & 107 & 0,000 & 1,000 \\
\hline Bicar & 46 & 38 & 0,762 & 0,383 \\
\hline Ciscar & 85 & 104 & 1,910 & 0,167 \\
\hline Comer & 107 & 107 & 0,000 & 1,000 \\
\hline $\begin{array}{l}\text { Empoleira } \\
\mathrm{r}\end{array}$ & 33 & 25 & 1,103 & 0,294 \\
\hline $\begin{array}{l}\text { Esticar } \\
\text { perna }\end{array}$ & 38 & 39 & 0,013 & 0,909 \\
\hline Ninho & 86 & 70 & 1,641 & 0,200 \\
\hline Perseguir & 6 & 8 & 0,286 & 0,593 \\
\hline Sentar & 27 & 38 & 1,862 & 0,172 \\
\hline
\end{tabular}

* Diferença significativa nas ocorrências de vídeos desse comportamento pelo teste de $\chi^{2}$.

As aves demonstraram preferência em expressar o comportamento banho de areia no período da tarde. Isto pode ter ocorrido como uma forma das aves perderem calor para o ambiente, uma vez que a movimentação das penas promove uma substancial termólise por convecção (Nääs, 1989; Silva, 2000), e que no período da tarde o ambiente é mais quente e durante o experimento ocorreram momentos em que o ITGU ficou acima do limite superior de conforto. Portanto, esse aumento de tempo de expressão do banho de areia não deve ser considerado como indicador de melhor bem-estar.

Apesar de não serem observadas diferenças entre os demais comportamentos na Tabela 4, verifica-se que os comportamentos comer, arrumar penas e beber água são muito frequentes, pois aparecem em todos os vídeos gravados. Os demais comportamentos provavelmente são expressos diariamente, porém com frequência menor ou em horários diferentes.

\section{CONCLUSÃO}

O ambiente térmico afetou os comportamentos das poedeiras e a melhor compreensão dos efeitos do ambiente térmico sobre os comportamentos das poedeiras pode possibilitar a inferência do bem estar das aves.

\section{AGRADECIMENTOS}

À Granja Kakimoto pela aves cedidas para o experimento, ao $\mathrm{CNPq}$ pelas bolsas de Iniciação Científica concedidas e à FAPESP pelo auxílio financeiro a esta pesquisa. 


\section{REFERÊNCIAS}

ALVES, S.P. Uso da zootecnia de precisão na avaliação de bem-estar climático em aves poedeiras em diferentes sistemas de criação. 2006. 128 p. Tese (Doutorado). Universidade de São Paulo, Piracicaba, 2006.

ALVINO, G. M.; ARCHER, G. S.; MENCH, J. A. Behavioural time budgets of broiler chickens reared in varying light intensities. Applied Animal Behaviour Science, v. 118, p. 54-61, 2009.

ARMSTRONG, D. V. Heat stress interaction with shade and cooling. Journal of Dairy Science, v.77, p.20442050, 1994.

BARBOSA FILHO, J. A. D.; SILVA, I. J. O.; SILVA, M. A. N.; SILVA, C. J. Avaliação dos comportamentos de aves poedeiras utilizando seqüência de imagens. Engenharia Agrícola, v.27, p. 93-99, 2007.

BECKER, B. G. Comportamento das aves e sua aplicação prática. In: CONFERÊNCIA APINCO DE CIÊNCIA E TECNOLOGIA AVÍCOLAS. 2002, Campinas. Anais. Campinas, 2005. p. 81-90.

BRACKE, M. B. M.; HOPSTER, H. Assessing the importance of natural behavior for animal welfare. Journal of Agricultural and Environmental Ethics, v. 19, p 77-89, 2006.

CAMPOS, E. J. O comportamento das aves. Revista Brasileira de Ciência Avícola, v. 2, p. 93-113, 2000.

CAMPOS, A. T; KLOSOWSKI, E. S; CAMPOS, A. T; CAMPOS, D. S.; CUNHA, A. R. Estimativa da produção de ovos para as diversas regiões do Paraná. In: CONGRESSO BRASILEIRO DE

AGROMETEOROLOGIA, 14, 2005, Campinas. Anais. Campinas, 2005, CD-ROM.

DAWKINS, M. S. The role of behaviour in the assessment of poultry welfare. World Poultry Science Journal v.55, p.295-303, 1999.

FERRANTE, V.; VERGA, M.; MANGIAGALLI, M. G.; CARENZI, C. Behaviour reactions, semen quality and testosterone levels in cocks: genetic implications. Animal Welfare, v.10, p.269-279, 2001.

HAAS, E. N., NIELSEN, B. L., BUITENHUIS, A. J., RODENBURG, T. B. Selection on feather pecking affects response to novelty and foraging behaviour in laying hens. Applied Animal Behaviour Science, v.124, p.90-96, 2010.

MEDEIROS, C. M., BAÊTA, F. C., OLIVEIRA, R. F. M., TINÔCO, I. F. F., ALBINO, L. F. T.; CECON, P. R. Efeitos da temperatura, umidade relativa e velocidade do ar em frangos de corte. Engenharia Agrícola, v.13, p. 277-286, 2005.

NÄÄS, I. A. Princípios de Conforto Térmico na

Produção Animal. São Paulo: Ícone. 1989. 180p.

NICOL, C. J., CAPLEN, G., EDGAR, J., BROWNE, W. J. Associations between welfare indicators and environmental choice in laying hens. Animal Behaviour, v.78, p.413-424, 2009.

PAYNE, G. C. Environmental temperature and egg production. In: HORTON-SMITH, C.; AMBROSE, E. C. (Eds.) The physiology of the domestic fowl. Scotland and London, Edinburgh: Oliver and Boyd, 1967. p. 235241.

PEREIRA, D. F. Ambiência em frangos de corte. In: CONFERÊNCIA APINCO 2011 DE CIÊNCIA E TECNOLOGIA AVÍCOLAS, 2011, Santos. Anais. Campinas-SP: Fundação APINCO de Ciência de Tecnologia Avícolas-FACTA, 2011, p. 113-122.

PEREIRA, D. F.; NÄÄS, I. A. Estimativa do conforto de matrizes de frango de corte baseada em análise do comportamento de preferência térmica. Engenharia Agrícola, v. 25, p. 315-321, 2005.

PEREIRA, D. F. ; NÄÄS, I. A.; ROMANINI, C. E. B.; SALGADO, D. D.; PEREIRA, G. O. T. Broiler breeder behavior and egg production as function of environmental temperature. Brazilian Journal of Poultry Science, v. 9, p. 9-16, 2007.

PEREIRA, D. F.; NÄÄS, I. A., ROMANINI, C. E. B.; SALGADO, D. D.; PEREIRA, G. O. T. Indicadores de bem-estar baseados em reações comportamentais de matrizes pesadas. Engenharia Agrícola, v. 25, p. 308314, 2005.

RIBER, A. B. Development with age of next box use and gregarious nesting in laying hens. Applied Animal Behaviour Science. v.123, p. 24-31, 2010.

RODRIGUES, V. C. Distribuição espacial e bem-estar de aves poedeiras em condições de estresse térmico utilizando visão computacional e inteligência artificial. 2006. 101p. Dissertação (Mestrado) - Universidade de São Paulo, Piracicaba.

SALGADO, D. D. Modelo estatístico para predição de bem-estar de reprodutoras de frango de corte baseado em dados de ambiente e análise de comportamento. 2006. 113p. Dissertação (Mestrado) - Universidade Estadual de Campinas, Campinas.

SALGADO, D. D.; NÄÄS, I. A. Avaliação de risco à produção de frango de corte do estado de São Paulo em função da temperatura ambiente. Engenharia Agrícola, v.30, p.367-376, 2010. 
SALGADO, D. D.; NÄÄS, I. A.; PEREIRA, D. F.; MOURA, D. J. Modelos estatísticos indicadores de comportamentos associados a bem-estar térmico para matrizes pesadas. Engenharia Agrícola, v. 27, p. 619629, 2007.

SCHWEAN-LARDNER, K.; CLASSEN, H. Lighting for broilers. USA: Aviagen, 2010. 39p. Disponível em: http://en.aviagen.com/assets/Tech_Center/Broiler_Breed er_Tech_Articles/English/LightingforBroilers1.pdf. Acesso em: 21 fev. 2013.

SILVA, R. G. Introdução à Bioclimatologia Animal. São Paulo: Nobel. 2000, 286p.

SILVA, I. J. O.; BARBOSA, F. J. A. D.; SILVA, M. A. N.; PIEDADE, S. M S. Influência do sistema de criação nos parâmetros comportamentais de duas linhagens de poedeiras submetidas a duas condições ambientais.

Revista Brasileira de Zootecnia, v. 35, p. 1439-1446, 2006.

TANKSON, J. D.; VIZZIER-THAXTON, Y.;

THAXTON, J.P.; MAY, J. D.; CAMERON, J.A. Stress and nutritional quality of broilers. Poultry Science, v.80, p.1384-1389, 2001.

WEEKS, C. A.; NICOL, C. J. Behavioural needs, priorities and preferences of laying hens. World's Poultry Science Journal, v. 62, p. 296-307, 2006. 